\title{
Increased Complication Rates After Hip and Knee Arthroplasty in Patients With Cirrhosis of the Liver
}

\author{
John V. Tiberi III MD, Viktor Hansen MD, \\ Naglaa El-Abbadi MS, MPH, Hany Bedair MD
}

Received: 13 December 2013/Accepted: 5 May 2014/Published online: 4 July 2014

(C) The Association of Bone and Joint Surgeons (R 2014

\begin{abstract}
Background Risk stratification is critical in patients with cirrhosis undergoing THAs and TKAs, as they may be more likely to have serious medical and surgical complications. As opposed to the Child-Pugh scoring system, which has limited use for orthopaedic surgeons inexperienced in assessing ascites and hepatic encephalopathy, the
\end{abstract}

Each author certifies that he or she, or a member of his or her immediate family, has no funding or commercial associations (eg, consultancies, stock ownership, equity interest, patent/licensing arrangements, etc) that might pose a conflict of interest in connection with the submitted article.

All ICMJE Conflict of Interest Forms for authors and Clinical Orthopaedics and Related Research editors and board members are on file with the publication and can be viewed on request.

Each author certifies that his or her institution approved the human protocol for this investigation, that all investigations were conducted in conformity with ethical principles of research. Informed consent was deemed unnecessary by our institutional review board.

J. V. Tiberi III ( $₫)$, H. Bedair

Department of Orthopaedic Surgery, Massachusetts General

Hospital, 55 Fruit Street, Boston, MA 02114, USA

e-mail: jvtiberi@gmail.com

J. V. Tiberi III, H. Bedair

Harvard Medical School, Boston, MA, USA

V. Hansen

Harris Orthopaedic Laboratory, Massachusetts General Hospital, Boston, MA, USA

N. El-Abbadi

Friedman School of Nutrition Science and Policy, Tufts

University, Boston, MA, USA

H. Bedair

Kaplan Center for Joint Reconstruction Surgery, Newton, MA, USA
Model for End-stage Liver Disease (MELD) is an easily calculated, validated scoring system for severity of liver disease based on common laboratory values; however, its usefulness for predicting complications after elective arthroplasty has not been studied.

Questions/purposes The purposes of this study were to determine the differences between patients with cirrhosis and control subjects in (1) hospital length of stay, discharge disposition, and readmission within 90 days; (2) early postoperative (90 days) medical complications potentially related to liver disease; (3) surgical complications within 90 days and any time after the procedure; (4) mortality rates after THA and TKA; and in addition, (5) to use the MELD score as a predictor for risk of complications and mortality.

Methods Institutional database query software used coding data identified 115 patients with liver cirrhosis before having THAs or TKAs from 2000 to 2012 and 115 control subjects without cirrhosis matched by age, sex, procedure, and year of surgery. Early postoperative and longer-term medical and surgical complications were compared. Regression analysis was used to determine a MELD score that predicted greater risk of complications.

Results Compared with matched control subjects, patients with cirrhosis had prolonged length of stay and higher rates of discharge to nursing facilities, readmission in 90 days, and urinary tract infections $(\mathrm{p}<0.01)$, renal failure $(p=0.03)$, blood transfusions $(p<0.01)$, gastrointestinal hemorrhage $(p=0.04)$, dislocations $(p=0.01)$, infections $(p=0.02)$, and revisions $(p=0.04)$ within 90 days. One-year $(\mathrm{p}=0.01)$ and longer-term $(\mathrm{p}=0.0002)$ mortality rates were greater in patients with cirrhosis. A MELD score of 10 or greater predicted a three times increased likelihood (odds ratio [OR]) of any complication (95\% CI, 1.28-7.00; $\mathrm{p}=0.01)$ and 4.1 times 
increased likelihood (OR) of death (95\% CI, 1.42-11.86; $\mathrm{p}<0.01)$.

Conclusions Patients with cirrhosis undergoing THAs and TKAs should be counseled regarding their increased risk of medical complications, surgical complications, and death. A MELD score of 10 or greater is associated with a high rate of complications, although this finding needs further validation because we were unable to control for all medical confounders.

Level of Evidence Level III, prognostic study. See the Instructions for Authors for a complete description of levels of evidence.

\section{Introduction}

THAs and TKAs have proven to be effective surgical procedures. For patient care and economic reasons, there has been an increasing interest in identifying risk factors for complications and poor outcomes [13]. Cirrhosis of the liver, irreversible fibrosis of liver tissue leading to hepatic dysfunction, is a known risk factor for complications after THA and TKA. However, studies of patients with cirrhosis undergoing THAs and TKAs generally have numerous shortcomings, including lack of a control group [8], small sample sizes $[7,8,15]$, contradictory results (increased [8, 15] versus no increased risk [7] of complications), and the use of the Child-Pugh $[5,14]$ classification as a measure of disease severity $[7-9,12,15]$.

The Child-Pugh $[5,14]$ system has limited clinical use for orthopaedic surgeons for preoperative risk assessment of THAs and TKAs because it involves a subjective assessment of ascites and encephalopathy, entities that rarely are assessed by many orthopaedic surgeons. The Model for End-stage Liver Disease (MELD) [11] score originally was developed to predict survival in patients undergoing transjugular intrahepatic portosystemic shunts, but subsequently was deemed a valid measure of mortality and risk disease severity for patients with end-stage liver disease [10]. The MELD score is based on serum creatinine, serum bilirubin, and the International Normalized Ratio (INR) for prothrombin time. It generally is considered as effective as, if not more effective as the Child-Pugh classification [6], and it is easier to calculate. The MELD score currently is used by the United Network for Organ Sharing to prioritize liver allocation to potential recipients; however, to our knowledge, it has not been evaluated in elective arthroplasty as a predictive tool of perioperative complications and mortality.

The purposes of our study were to determine the differences between patients undergoing elective THAs or TKAs with cirrhosis compared with matched control subjects in (1) hospital length of stay, discharge disposition, and readmission within 90 days; (2) early postoperative (90 days) medical complications potentially related to liver disease (urinary tract infection, acute renal failure, blood transfusion, gastrointestinal hemorrhage); (3) surgical complications (infection, dislocation, reoperation, revision) within 90 days and any time after the procedure; (4) mortality; and in addition, (5) to use the MELD score as a predictor for risk of complications and mortality.

\section{Patients and Methods}

We conducted a retrospective case-control study using diagnosis and procedure coding information to query our institutional database to identify all patients with a diagnosis of cirrhosis of the liver undergoing an elective THA or TKA for end-stage degenerative joint disease and for whom conservative treatments failed. The study inclusion dates were January 1, 2000 through November 30, 2012 without any exclusion criteria. One hundred-fifteen patients (60 THAs, 55 TKAs) were identified and included in the analysis. There were 59 male and 56 female patients with a mean age of 62.9 years and a minimum followup of 3 months (mean, 4.4 years; range, 3 months-12.1 years). Using the institutional database software, a group of patients without cirrhosis who underwent THA or TKA for end-stage degenerative joint disease matched (1:1) for year of surgery, age, sex, and surgically treated joint was randomly generated and served as a control group. All 230 patients were followed up with a clinical evaluation and radiographic assessment.

The database software uses coding and demographic data to identify all variables. Details regarding these variables were confirmed with chart review by at least one of the authors. Length of stay and discharge disposition (home versus short-term rehabilitation facility) with respect to the admission associated with the procedure were obtained. The early postoperative period was defined as 90 days from the procedure. Early postoperative outcomes included readmission, medical complications (urinary tract infection, blood transfusion, acute renal failure, gastrointestinal hemorrhage), and surgical complications (reoperation, revision, infection, dislocation). The occurrence of select surgical complications (infection, reoperation, revision) also were evaluated for the entire postoperative period. Ninety days, 1-year, and any time mortality rates were compared.

For the patients with cirrhosis of the liver, the medical records were reviewed to obtain serum creatinine, serum total bilirubin, and INR immediately before the procedure. The MELD score was calculated according to the following formula: 
Table 1. Perioperative admission and discharge requirements

\begin{tabular}{|c|c|c|c|}
\hline $\begin{array}{l}\text { Admission/discharge } \\
\text { variable }\end{array}$ & $\begin{array}{l}\text { Patients with } \\
\text { cirrhosis* }\end{array}$ & $\begin{array}{l}\text { Control } \\
\text { subjects }\end{array}$ & $\mathrm{p}$ value \\
\hline Length of stay (days) & $5.3(2-51)$ & $4.2(2-13)$ & 0.03 \\
\hline Discharge home & $47(41 \%)$ & $64(56 \%)$ & 0.03 \\
\hline $\begin{array}{l}\text { Discharge to } \\
\text { rehabilitation facility }\end{array}$ & $67(59 \%)$ & $51(44 \%)$ & \\
\hline Readmission (90 days) & $12(10 \%)$ & $2(2 \%)$ & 0.006 \\
\hline
\end{tabular}

* One patient died on postoperative Day 2 and therefore not included

Table 2. Medical complications within 90 days after surgery

\begin{tabular}{llll}
\hline Complication & $\begin{array}{l}\text { Patients with } \\
\text { cirrhosis }\end{array}$ & $\begin{array}{l}\text { Control } \\
\text { subjects }\end{array}$ & $\mathrm{p}$ value \\
\hline Urinary tract infection & $14(12 \%)$ & $3(3 \%)$ & 0.006 \\
Acute renal failure & $11(10 \%)$ & $1(1 \%)$ & 0.003 \\
$\begin{array}{l}\text { Transfusion } \\
\text { Gastrointestinal } \\
\text { hemorrhage }\end{array}$ & $26(23 \%)$ & $8(7 \%)$ & 0.0008 \\
\hline
\end{tabular}

$$
\begin{aligned}
\text { MELD }= & 10 \times[(0.957 \times \text { Ln serumcreatinine }) \\
& +(0.378 \times \text { Ln serum totalbilirubin }) \\
& +(1.12 \times \text { Ln INR })+0.643)]
\end{aligned}
$$

Where $\mathrm{Ln}$ is the natural logarithm and serum creatinine and serum total bilirubin are expressed in $\mathrm{mg} / \mathrm{dL}$ [16]. For the purposes of the calculation, all minimum laboratory values are 1 (values less than 1 are entered as 1 ), the maximum serum creatinine is $4 \mathrm{mg} / \mathrm{dL}$, and any patient receiving dialysis twice or 24 hours of continuous venovenous hemodialysis within 1 week of the serum creatinine drawing automatically had $4 \mathrm{mg} / \mathrm{dL}$ entered regardless of the actual value [16]. Ten patients were excluded from the MELD score analysis owing to lack of appropriate laboratory tests.

Continuous variables were compared statistically using a t-test and categorical values were compared using chisquare. Regression analysis was used to determine a threshold MELD score that predicted greater risk of complications among patients with cirrhosis.

\section{Results}

Patients with cirrhosis had a longer length of stay, more frequent discharge to a skilled nursing or short-term rehabilitation facility compared with discharge home, and more early postoperative hospital readmissions (Table 1).

Within 90 days of the procedure, patients with cirrhosis had higher rates of renal complications, including urinary tract infection, acute renal failure, blood transfusion, and gastrointestinal hemorrhage (Table 2).
Table 3. Surgical complications within 90 days after surgery

\begin{tabular}{llll}
\hline Complication & $\begin{array}{l}\text { Patients with } \\
\text { cirrhosis }\end{array}$ & $\begin{array}{l}\text { Control } \\
\text { subjects }\end{array}$ & p value \\
\hline $\begin{array}{l}\text { Dislocations } \\
(\mathrm{n}=60)\end{array}$ & $6(10 \%)$ & 0 & 0.01 \\
Infections & $5(4 \%)$ & 0 & 0.02 \\
Reoperations & $3(3 \%)$ & $2(2 \%)$ & 0.65 \\
Revision surgery & $4(3 \%)$ & 0 & 0.04 \\
\hline
\end{tabular}

Table 4. Surgical complications during followup

\begin{tabular}{llll}
\hline Complication & $\begin{array}{l}\text { Patients with } \\
\text { cirrhosis }\end{array}$ & $\begin{array}{l}\text { Control } \\
\text { subjects }\end{array}$ & p value \\
\hline Infections & $7(6 \%)$ & $2(2 \%)$ & 0.09 \\
Reoperations & $6(5 \%)$ & $4(3 \%)$ & 0.52 \\
Revision surgery & $5(4 \%)$ & $2(2 \%)$ & 0.25 \\
\hline
\end{tabular}

Table 5. Mortality rates

\begin{tabular}{lcll}
\hline Time & $\begin{array}{l}\text { Patients with } \\
\text { cirrhosis }\end{array}$ & $\begin{array}{l}\text { Control } \\
\text { subjects }\end{array}$ & p value \\
\hline $\begin{array}{l}\text { Perioperative } \\
\quad 90 \text { days })\end{array}$ & $1(1 \%)$ & 0 & 0.32 \\
$\begin{array}{l}\text { One-year followup } \\
\begin{array}{l}\text { Most recent } \\
\text { followup }\end{array}\end{array}$ & $6(5 \%)$ & 0 & 0.01 \\
\hline
\end{tabular}

Within 90 days of the procedure, patients with cirrhosis had greater numbers of hip dislocations, infections, and revision surgeries (Table 3). There was no difference in the number of reoperations without removal or change of components. The rates of infection, reoperation, or revision during followup were not statistically different (Table 4).

The overall and 1-year mortality rates were greater in the patients with cirrhosis (Table 5), although there was no difference in the early postoperative mortality rate.

MELD scores of 10 or greater were associated with increased medical and surgical complications in patients with cirrhosis (Table 6).

\section{Discussion}

Risk stratification is important for any patient undergoing a THA or TKA. Cirrhosis of the liver generally is considered a major medical comorbidity; however, prior studies on this subject have had conflicting results [7-9, 12, 15]. Although most patients undergoing THAs or TKAs are evaluated by an internist or primary care physician before the procedure, the orthopaedic surgeon is in the best and 
Table 6. Correlation of MELD score with complication rates

\begin{tabular}{lcccc}
\hline Complication & $\begin{array}{l}\text { MELD }<10 \\
(\mathrm{n}=71)\end{array}$ & $\begin{array}{l}\text { MELD } \geq 10 \\
(\mathrm{n}=34)\end{array}$ & $\begin{array}{l}\text { p value } \\
(\text { MELD }<10 \text { vs } \geq 10)\end{array}$ & $\begin{array}{l}\text { Odds ratio (95\% CI) } \\
(\text { MELD }<10 \text { vs } \geq 10)\end{array}$ \\
\hline Medical & $24(34 \%)$ & $21(62 \%)$ & $<0.01$ & $3.16(1.35-7.39)$ \\
Surgical & $5(7 \%)$ & $9(26 \%)$ & $<0.01$ & $4.75(1.45-15.56)$ \\
Any & $27(38 \%)$ & $22(65 \%)$ & 0.01 & $2.99(1.28-7.00)$ \\
Death & $7(10 \%)$ & $11(32 \%)$ & $<0.01$ & $4.10(1.42-11.86)$ \\
\hline
\end{tabular}

MELD $=$ Model for End-stage Liver Disease

most appropriate position to counsel patients regarding the indications and risks; therefore, an effective, easily used risk stratification system such as the MELD score, offers substantial advantages over the Child-Pugh score. In our study, patients with cirrhosis had greater postoperative care requirements in terms of hospital stay, discharge to nursing facilities; higher rates of readmission and several medical and surgical complications during the early postoperative period; and greater 1-year and lifetime mortality rates. The MELD score predicted postoperative morbidity and mortality.

Our study has several limitations. First, we did not control for comorbidities to isolate cirrhosis as the only difference between the groups. There are many comorbid conditions that may be correlated with perioperative complications and mortality that may confound the conclusions of this study. We attempted to reduce this confounding effect by randomly selecting control group patients in the matching criteria. The goal of our study, however, was not to draw a conclusion of causation, but rather one of correlation between cirrhosis and greater complication and mortality rates. Therefore the results of the study should be interpreted with this understanding. Second, although the time from surgery was a controlled variable, there could be some underlying transfer bias given the likely better medical condition and outcomes associated with the control group. This bias would be expected to affect predominantly long-term minor complications and less likely to affect the major long-term complications we studied (infection, reoperation, revision). Another limitation is the use of coding data, because some diagnoses may be underreported. This limitation more likely would affect more minor medical conditions, such as urinary tract infection or superficial infection not requiring reoperation or revision, as opposed to major surgical complications, which almost certainly would be coded.

Patients with cirrhosis had a longer length of hospital stay, more frequent discharge to a skilled nursing or shortterm rehabilitation facility, and greater early postoperative readmission rate. The prolonged length of stay is in accordance with previous reports [7, 9]; however, to our knowledge, there is no published study that has evaluated disposition requirements or readmission rates. Our findings likely are related to the underlying morbidity of these patients and the increased early postoperative medical and surgical complications.

Rates of urinary tract infection, blood transfusion, acute renal failure, and gastrointestinal hemorrhage within 90 days of the procedure were greater in patients with cirrhosis. Our transfusion data were contrary to those reported by Shih et al. [15] (no difference between patients with cirrhosis and control subjects after TKA) and Cohen et al. [7] (increased transfusion requirement for emergent THA but not elective THA in patients with cirrhosis versus control subjects). Rates of urinary tract infection (range, $2 \%-5 \%)[9,15]$, acute renal failure (5\%) [9], and gastrointestinal hemorrhage (range, 2\%-5\%) [9, 15] have been reported in contrast to our $12 \%$ rate; however, these studies did not directly compare these rates with those of the control subjects.

Rates of hip dislocation, infection, and revision were greater in these patients within 90 days of the procedure; however, these differences were not observed when evaluated as occurring at any time during the postoperative period. This may indicate that patients with cirrhosis have a greater early postoperative surgical risk but not a longerterm one. Hsieh et al. [9] reported a $22.2 \%$ infection rate and $22.2 \%$ 5-year failure rate in patients with cirrhosis after THA. Shih et al. [15] reported five early and one late infection and one revision after 51 TKAs in patients with cirrhosis. Cohen et al. [7] found no difference in dislocation, infection, or revision rates compared with those of control subjects. In our study, mortality rates were greater at 1-year and at any time after surgery, but not within 90 days, in patients with cirrhosis compared with control subjects. Shih et al. [15] reported a much higher (36\% versus $5 \%$ ) mortality rate in patients with cirrhosis after TKA despite a longer mean followup for control subjects (42 versus 74 months). They identified hepatoma as an independent risk factor for mortality. Cohen et al. [7] reported an increased mortality rate for emergent THAs, but not elective arthroplasties. What remains unknown is whether patients with cirrhosis undergoing a THA or TKA have a greater or lesser mortality rate compared with patients matched for severity (MELD or Child-Pugh) who did not undergo these procedures; further investigation to 
answer this question also would help establish the indications for arthroplasty in these patients.

We also found correlation of the rate of complications with the MELD $[10,11]$ score for patients with cirrhosis. The Child-Pugh system has little clinical use to orthopaedic surgeons who are unfamiliar with grading ascites or hepatic encephalopathy without the assistance of an internist or gastroenterologist. The MELD score is based on common, routinely obtained, and objective laboratory values. Multiple free online calculators are available to calculate the MELD score by providing serum creatinine, serum total bilirubin, and INR values. In our study, a MELD score of 10 or greater was associated with an increased likelihood of medical complications (OR, 3.2), surgical complications (OR, 4.8), and death $(\mathrm{OR}, 4.1)$ compared with patients with cirrhosis with a MELD score less than 10. In contrast to some previous studies which disagree whether the severity of cirrhosis correlates with the development of complications [7, 9, and 15], our study showed that nonsurgical treatment alternatives should be considered in this population.

However, we could not control for other potentially relevant confounding variables, such as alcoholism, hepatitis, and overall level of medical infirmity, all of which have been associated with complications after arthroplasty [1-4], and which may be more common in patients with cirrhosis. We therefore consider our finding on the MELD score to be preliminary, and it needs to be validated by future studies that are able to control for those confounding variables.

Patients with cirrhosis undergoing THAs and TKAs are at increased risk for medical and surgical complications. When considering a THA or TKA, we recommend using the MELD score rather than the Child-Pugh score for the purposes of indicating and risk-stratifying patients with cirrhosis. Risks are greatest in patients with cirrhosis with a MELD score of 10 or greater and alternatives to THA and TKA should be considered in these patients. Appropriate patient counseling is advised if a procedure is needed.

\section{References}

1. Bozic KJ, Lau E, Kurtz S, Ong K, Berry DJ. Patient-related risk factors for postoperative mortality and periprosthetic joint infection in medicare patients undergoing TKA. Clin Orthop Relat Res. 2012; 470:130-137.
2. Bozic KJ, Lau E, Kurtz S, Ong K, Rubash H, Vail TP, Berry DJ. Patient-related risk factors for periprosthetic joint infection and postoperative mortality following total hip arthroplasty in Medicare patients. J Bone Joint Surg Am. 2012; 94:794-800.

3. Bozic KJ, Lau E, Ong K, Chan V, Kurtz S, Vail TP, Rubash HE, Berry DJ. Risk factors for early revision after primary TKA in Medicare patients. Clin Orthop Relat Res. 2014; 472:232-237.

4. Bozic KJ, Lau E, Ong K, Chan V, Kurtz S, Vail TP, Rubash HE, Berry DJ. Risk factors for early revision after primary total hip arthroplasty in Medicare patients. Clin Orthop Relat Res. 2014; 472:449-454.

5. Child CG, Turcotte JG. Surgery and portal hypertension. In: Child CG, Ed. The Liver and Portal Hypertension. Philadelphia, PA: WB Saunders; 1964:50-64.

6. Cholongitas E, Papatheodoridis GV, Vangeli M, Terreni N, Patch D, Burroughs AK. Systematic review: the model for end-stage liver disease: should it replace Child-Pugh's classification for assessing prognosis in cirrhosis? Aliment Pharmacol Ther. 2005; 22:1079-1089.

7. Cohen SM, Te HS, Levitsky J. Operative risk of total hip and knee arthroplasty in cirrhotic patients. J Arthroplasty. 2005; 20:460-466.

8. Hsieh PH, Chen LH, Lee MS, Chen CH, Yang WE, Shih CH. Hip arthroplasty in patients with cirrhosis of the liver. J Bone Joint Surg Br. 2003; 85:818-821.

9. Hsieh PH, Ueng SW, Lee MS, Shih HN, Huang KC. Prosthetic hip infection in patients with liver cirrhosis: an outcome analysis. Int J Infect Dis. 2010; 14:e1054-1059.

10. Kamath PS, Wiesner RH, Malinchoc M, Kremers W, Therneau TM, Kosberg CL, D’Amico G, Dickson ER, Kim WR. A model to predict survival in patients with end-stage liver disease. Hepatology. 2001; 33:464-470.

11. Malinchoc M, Kamath PS, Gordon FD, Peine CJ, Rank J, terBorg PL. A model to predict poor survival in patients undergoing tranjugular intrahepatic portosystemic shunts. Hepatology. 2000; 31:864-871.

12. Moon YW, Kim YS, Kwon SY, Kim SY, Lim SJ, Park YS. Perioperative risk of hip arthroplasty in patients with cirrhotic liver disease. J Korean Med Sci. 2007; 22:223-226.

13. Paxton EW, Nambe RS, Maletis GB, Khatod M, Yue EJ, Davies M, Low RB Jr, Wyatt RW, Inacio MC, Funahashi TT. A prospective study of 80,000 total joint and 5000 anterior cruciate ligament reconstruction procedures in a community-based registry in the United States. J Bone Joint Surg Am. 2010; 92(suppl 2):117-132.

14. Pugh RN, Murray-Lyon IM, Dawson JL, Pietroni MC, Williams $\mathrm{R}$. Transection of the oesophagus for bleeding oesophageal varices. Br J Surg. 1973; 60:646-649.

15. Shih LY, Cheng CY, Chang CH, Hsu KY, Hsu RW, Shih HN. Total knee arthroplasty in patients with liver cirrhosis. $J$ Bone Joint Surg Am. 2004; 86:335-341.

16. UNOS org (United Netword for Organ Sharing). MELD/PELD calculator documentation. Available at: http://www.unos.org/ docs/MELD_PELD_Calculator_Documentation.pdf. Accessed November 30, 2012. 